\title{
PERSEMBAHYANGAN DAN PAWINTENAN SARASWATI BAGI SISWA BARU DI SD NO. 1 DENBANTAS (Kajian Pendidikan Agama Hindu)
}

\author{
Desak Nyoman Seniwati \\ Fakultas Ilmu Agama dan Kebudayaan \\ Universitas Hindu Indonesia Denpasar \\ e-mail: desakseniwati1960@gmail.com
}

\author{
I Gst. Ayu Wahyu Marhaenningrat \\ Fakultas Ilmu Agama dan Kebudayaan \\ Universitas Hindu Indonesia \\ Denpasar
}

\begin{abstract}
This research entitled worship Saraswati and Pawintenan Saraswati for New Students in SD No. 1 Denbantas The Study of Hindu Religious Education. In essence want to study about the procedure of the implementation of the ceremony worship Saraswati in terms of Hindu Religious Education. The background of this research is the desire to understand more deeply about the process, the philosophical meaning and the values of education contained in the implementation of Saraswati prayer and Saraswati pawintenan for new students. 1 Denbantas, Tabanan Sub-district, Tabanan District. The results of this study can be described as follows: Saraswati and Saraswati process for new students in elementary school. 1 Denbantas, carried out in the following ceremonial sequences: preparation stage, by preparing ceremonial means of Bantas Saraswati. Upakara (banten) is placed in such a way in front of the Padma school side by side with the place of libraries or books of knowledge which is the phantom stance of Sang Hyang Saraswati who will be married. Implementation stage; Saraswati prayers and Saraswati pawintenan for new students is heated by a Tri Khayangan leader who begins with mebyakala, then proceed with the purification ceremony that is meprayascita which aims to purify upakara and all people (teachers and students) who will participate or involved in the prayer intended. The next activity is the main ceremony of Saraswati prayer ceremony that is the worship of the majesty and greatness of Ida Sang Hyang Saraswati who has lowered the science to mankind. The value of tattwa lies in the forms of bebantenan (reringgitan, tetuasan, etc).
\end{abstract}

Keywords: Saraswati and Pawintenan Saraswati for New Students of Hindu Religious Education Study 


\begin{abstract}
Abstrak
Penelitian ini berjudul Persembahyangan Saraswati dan Pawintenan Saraswati bagi Siswa Baru di SD No. 1 Denbantas Kajian Pendidikan Agama Hindu. Pada intinya ingin mengkaji tentang tata cara pelaksanaan upacara Persembahyangan Saraswati ditinjau dari Pendidikan Agama Hindu. Latar belakang dilakukannya penelitian ini adalah adanya keinginan untuk memahami secara lebih mendalam mengenai proses, makna filosofis serta nilai-nilai pendidikan yang terkandung dalam pelaksanaan persembahyangan Saraswati dan pawintenan Saraswati bagi siswa baru SD No. 1 Denbantas, Kecamatan Tabanan, Kabupaten Tabanan. Hasil penelitian ini dapat diuraikan sebagai berikut: proses persembahyangan Saraswati dan pawintenan Saraswati bagi siswa baru di SD No. 1 Denbantas, dilaksanakan dengan urutan-urutan upacara sebagai berikut: tahap persiapan, dengan menyiapkan saranasarana upacara berupa banten Saraswati. Upakara (banten) tersebut ditempatkan sedemikian rupa dihadapan pelinggih Padma sekolah berdampingan dengan tempat pustaka-pustaka atau buku pengetahuan yang merupakan lingga stana Sang Hyang Saraswati yang akan diupacarai. Tahap pelaksanaan; persembahyangan Saraswati dan pawintenan Saraswati bagi siswa baru dipuput oleh seorang pemangku Tri Khayangan yang diawali dengan mebyakala, kemudian dilanjutkan dengan upacara penyucian yaitu meprayascita yang bertujuan untuk menyucikan upakara maupun semua umat (guru dan siswa) yang akan ikut atau terlibat dalam persembahyangan dimaksud. Kegiatan selanjutnya adalah upacara pokok yakni upacara persembahyangan Saraswati yakni pemujaan terhadap keagungan dan kebesaran Ida Sang Hyang Saraswati yang telah menurunkan ilmu pengetahuan kepada umat manusia. Nilai tattwa terletak pada bentuk-bentuk bebantenan (reringgitan, tetuasan, dsbnya).
\end{abstract}

Kata Kunci: Persembahyangan Saraswati dan Pawintenan Saraswati bagi Siswa Baru Kajian Pendidikan Agama Hindu

\subsection{Pendahuluan}

Perayaan Saraswati merupakan peringatan turunnya ilmu pengetahuan dengan pemujaan ditujukan kehadapan Sang Hyang Aji Saraswati sebagai sumber Ilmu Pengetahuan. Perayaan Saraswati umumnya dirayakan oleh seluruh umat Hindu, para pelajar, guru-guru, cendikiawan warga masyarakat baik di sekolah-sekolah, kantorkantor, rumah-rumah, maupun dalam lingkungan masyarakat. Sebagaimana halnya perayaan hari Saraswati yang dilaksanakan oleh Sekolah Dasar No. 1 Denbantas yang berlokasi di Banjar Tuakilang Belodan Desa Denbantas kecamatan Tabanan yang secara rutin melaksanakan upacara persembahyangan bersama dengan melibatkan seluruh komponen yang ada di sekolah tersebut sebagai salah satu upaya mengaplikasikan ilmu yang secara teoritis diperoleh di bangku sekolah untuk dilaksanakan dan diamalkan dalam kehidupan sehari-hari.

Dalam pelaksanaan kegiatan persembahyangan dimaksud semua siswa, guru, maupun staf administrasi SD No. 1 Denbantas diwajibkan untuk mengikuti persembahyangan tersebut, hal ini dimaksudkan agar sekolah tersebut dapat memberi contoh dan menjadi panutan bagi 
masyarakat disekitarnya, dalam mewujudkan kesadaran serta tata cara pelaksanaan beragama yang benar. Secara umum pelaksanaan upacara persembahyangan piodalan Sanghyang Saraswati telah dilaksanakan secara rutin setiap 6 bulan sekali oleh Sekolah Dasar No. 1 Denbantas kecamatan Tabanan. Tetapi sampai sejauh ini belum dapat diketahui secara pasti apakah pelaksanaan persembahyangan hari saraswati yang telah dilaksanakan secara rutin oleh SD No. 1 Denbantas mampu meningkatkan kualitas moral dan keimanan dari anak didik.

\subsection{Konsep dan Teori}

Konsep dalam penulisan ini memuat uraian sistematis tentang pemikiran yang ada hubungannya dengan penelitian. Penulis mencari pengertian-pengertian atau konsepkonsep yang relevan dengan variabelvariabel yang menjadi topik penelitian, sehingga diperoleh pemahaman yang komprehensif terhadap permasalahan yang dikemukakan berturut-turut yaitu : Persembahyangan, Saraswati, Pawintenan Saraswati, Pendidikan Agama Hindu.

Dalam bukunya Sugiyono (2007 : 52) menjelaskan bahwa, Teori adalah seperangkat konstruk (konsep), definisi dan proposisi yang berfungsi untuk melihat fenomena secara sistematik, melalui sfesifikasi hubungan antar variabel, sehingga dapat berguna untuk menjelaskan dan meramalkan suatu fenomena. Teori dimaksudkan sebagai sesuatu yang mengandung prinsip dasar yang berlaku umum yang memberikan kerangka orientasi untuk analisis dan klasifikasi. Kerangka orientasi yang dimaksudkan adalah kerangka pikiran yang dirumuskan dengan jelas sebagai tuntunan untuk memecahkan masalah penelitian. Teori yang dipakai dalam penelitian ini antara lain : Teori Fungsional Struktural dan Teori Religi.

\subsection{Pembahasan}

Sekolah Dasar No. 1 Denbantas adalah salah satu Sekolah Dasar yang terletak di Br. Lingkungan Tuakilang Belodan Desa/ Kelurahan Denbantas Kecamatan Tabanan Kabupaten Tabanan Propinsi Bali. Sekolah Dasar ini didirikan pada tanggal 1 April 1948 dengan Beslit dari $6116 \mathrm{KDH}$. TK I. Bali tertanggal 18 Juni 1973, No. 27 dengan batas-batas sbb : Di sebelah utara : Kantor Panwaslu Kabupaten Tabanan, sebelah Timur : Jalan Raya Batukaru, sebelah selatan : Kantor Kepala Desa Denbantas dan disebelah barat: Rumah Penduduk.

Luas areal sekolah : 37,70 are dengan peruntukan sebagai berikut: 25,23 are digunakan untuk bangunan dan 12,47 are untuk halaman bermain anak-anak serta sebuah bangunan padmasana sebagai Parahyangan untuk memuja keagungan Ida Sang Hyang Widhi Wasa atau stananya Ida Sang Hyang Widhi dalam wujud Ista Dewata. Wujud nyata dari kegiatan yang secara rutinitas dilaksanakan adalah setiap rerahinan purnama, tilem, dan hari raya besar lainnya seperti piodalan saraswati. Sebagai pawongan telah dibangun kantor kepala sekolah, ruang guru, dan ruangan / kelas untuk kegiatan belajar mengajar.

Sebagai palemahan telah ditatanya pertamanan yang rapi dan indah di lingkungan sekolah yang dilengkapi dengan kantin dan WC / toilet umum, dalam arti toilet yang diperuntukkan bagi kepentingan para murid / siswa.

Jumlah keseluruhan guru dan pegawai SD No. 1 Denbantas sampai dengan bulan Oktober 2013 tahun ajaran 2012 / 2013 berjumlah : 14 orang. Terdiri dari : satu orang kepala sekolah, 2 orang guru agama, 1 orang guru orkes, 4 orang guru kelas atau guru umum, 5 orang guru pengabdian dan 1 orang berstatus sebagai penjaga sekolah. Untuk kelancaran perjalanan proses pendidikan di sekolah tersebut, selain peran 
guru dan pegawai-pegawai yang formal terdapat pula dukungan dari pihak-pihak lain yang bersifat informal khususnya dari pihak orang tua murid maupun masyarakat disekitarnya yang tergabung dalam suatu wadah yang disebut komite sekolah. Peran komite sekolah sangat penting dalam rangka mendukung kelangsungan proses kegiatan belajar mengajar. Tanpa adanya dukungan orang tua murid dan masyarakat (komite sekolah) niscaya proses belajar mengajar tidak akan dapat berlangsung optimal sesuai dengan harapan para siswa, guru maupun orang tua murid.

\subsubsection{Persembahyangan Saraswati dan Pawintenan Saraswati}

Setiap hari sabtu umanis watugunung diperingati sebagai hari raya saraswati. Perayaan saraswati merupakan peringatan turunnya ilmu pengetahuan. Pemujaan pada hari saraswati ditujukan kehadapan Sang Hyang Aji Saraswati sebagai sumber ilmu pengetahuan. Saraswati bermakna sebagai dewanya kata-kata, pengetahuan dan kebijaksanaan. Perayaan Saraswati pada umumnya dirayakan oleh seluruh umat Hindu; para pelajar, guru-guru, cendikiawan, warga masyarakat baik di sekolah-sekolah, kantor-kantor, rumah-rumah maupun dalam lingkungan masyarakat setempat. Dalam lontar Sundarigama yang diambil melalui internet dijelaskan bahwa :

Upacara pemujaan saraswati dilaksanakan pada pagi hari atau sebelum tengah hari, apabila dilaksanakan pada siang hari maka dianggap kurang bermanfaat; hal itu disebabkan karena Hyang Saraswati sudah kembali ke stananya (tempatnya). Pada hari itu juga sebelum tengah hari tidak diperkenankan untuk melakukan kegiatan membaca dan menulis mantra atau kesusastraan. Hal ini dimaksudkan agar Hyang Saraswati senantiasa menganugerahkan sinar sucinya berupa pengetahuan kepada kita semua. Dewi Saraswati diwujudkan dengan aksara "Om Kara" dan dipersonifikasikan sebagai wanita cantik bertangan empat, memegang daun lontar, teratai, genitri, rebab dan disekitarnya ada burung merak dan angsa.

Adapun makna simbolis yang terkandung di dalamnya adalah sebagai berikut :

- Wanita cantik bermakna : bahwa ilmu pengetahuan memberi daya tarik dan disenangi oleh setiap orang.

- $\quad$ Bertangan empat maknanya : sebagai kekuatan atau kemampuan untuk menjangkau segala arah.

- Wina bermakna bahwa : pengetahuan dapat memberi rasa indah, menarik dan estetis.

Genitri bermakna bahwa pengetahuan itu tiada habis-habisnya untuk dipelajari karena tidak berawal dan tidak berakhir.

- Daun Lontar bermakna sumber daripada ilmu pengetahuan.

- Bunga Teratai bermakna sebagai kesucian dari ilmu pengetahuan.

- Angsa bermakna sebagai suatu ketenangan dan kewaspadaan atau dengan pengetahuan dapat meningkatkan ketenangan dan kesadaran atau kewaspadaan diri.

- Burung merak sebagai lambang keagungan, kewibawaan, martabat yang mulia yang dapat membantu dan membahagiakan makhluk ciptaan Tuhan.

Semua buku-buku, kitab suci, lontarlontar maupun buku pengetahuan lainnya dikumpulkan pada suatu tempat untuk diupacarai dengan maksud agar Hyang Saraswati memberi sinar sucinya dengan menganugerahkan pengetahuan suci : setelah upacara selesai maka pada hari minggu paing wuku sinta dilanjutkan dengan upacara banyu pinaruh yang bertujuan untuk 
penyucian diri secara lahir maupun bathin.

Penyucian secara lahir biasanya dilakukan dengan mandi di sungai, danau, laut di tempat-tempat yang suci atau dengan menggunakan air kumkuman. Sedangkan penyucian bathinnya dilakukan dengan jalan memohon tirta saraswati.

Pelaksanaan banyu pinaruh ini tidak dilaksanakan di sekolah melainkan dilaksanakan di masing-masing rumah bersama sanak keluarga, sekaligus nglungsur atau ngelaba banten Saraswati. Dengan demikian seluruh rangkaian perayaan Hari Saraswati telah berakhir.

\subsubsection{Proses Pelaksanaan Persembah- yangan Saraswati dan Pawintenan Saraswati}

Dari pengamatan yang dilakukan diperoleh hasil tentang proses pelaksanaan persembahyangan yang dilaksanakan di SD No. 1 Denbantas dengan urutan-urutan upacara sebagai berikut :

\section{(a) Tahap Persiapan Persembahyangan}

Pada tahap persiapan, pelaksanaan upacara persembahyangan Saraswati diawali dengan menyiapkan sarana upacara dalam bentuk upakara (banten) oleh para guru-guru yang dikoordinir oleh guru agama. Adapun upakara (banten) piodalan Saraswati sebagai berikut.

$\begin{array}{ll}\text { - } & \text { Banten Byakala } \\ \text { - } & \text { Banten Prayascita } \\ \text { - } & \text { Pras pejati Jangkep } \\ \text { - } \quad \text { Banten Suci 1 Soroh } \\ \text { - } \quad \text { Jrimpen } \\ \text { - } \quad \text { Pengambyan } \\ \text { - } \quad \text { Pucak Manik } \\ \text { - } \quad \text { Beberapa Sesayut/ Tebasan seperti : } \\ \quad \text { Sesayut, Pebersihan, Amerta Dewa, } \\ \quad \text { Pengulang Dewa, Amukti Sakti dan } \\ \text { - Pajegan } \\ \text { - } \quad \text { Pebogan Sorohan }\end{array}$

- $\quad$ Banten Pawintenan Saraswati

- Ganjaran Agung

Upakara (Banten) tersebut diatas ditata sedemikian rupa, sedangkan pustakapustaka atau buku-buku pengetahuan lainnya termasuk alat-alat pelajaran yang merupakan lingga stana Hyang Saraswati diatur dan ditempatkan pada tempat yang layak untuk itu. Tirta yang dipergunakan hanya tirta (kekululuh) saraswati yang diperoleh dengan jalan memohon kehadapan Hyang Surya sekaligus merupakan tirta Saraswati yang ditempatkan pada lingga Saraswati.

\section{(b) Pelaksanaan Persembahyangan}

Upacara Persembahyangan Saraswati dan Pawintenan Saraswati bagi siswa baru di SD No. 1 Denbantas dipuput atau dilaksanakan oleh seorang pemangku tri khayangan yang diawali dengan pengastawa upakara atau banten pebyakalan, pemerayascita, ngayat betara, ngatur piuning serta nganteban upakara atau banten.

Pada saat yang bersamaan para siswa yang dipimpin oleh guru Agama diajak bersama-sama melantunkan kekidung warga sari sehingga tercipta suasana religius dalam persembahyangan dimaksud. Selanjutnya guru Agama yang sekaligus sebagai pengenter pada acara tersebut mengajak seluruh siswa dan guru untuk mempersiapkan acara pokok yaitu persembahyangan bersama, sebagaimana biasa dengan kramaning sembah. Namun sebelumnya diawali dengan melaksanakan puja trisandhya yang dipimpin oleh guru Agama. Puja Tri Sandhya terdiri dari enam bait, bait pertama atau sebagai Sandya Vandanam ( awal ) diambil dari Gayatri atau Savitri Mantram ( Rg Veda, Sama Veda, dan Yayur Veda) atau sering disebut dengan Gayatri mantram atau ibunya mantra. Setiap pelaksanaan puja Tri Sandhya hendaknya 
selalu didahului dengan penyucian diri (asucilaksana). Gayatri mantra terdapat dalam Yajur Veda XXVI.3. (Widana, 2009 : 45).

Adapun mantranya sebagai berikut :

a) Sikap Duduk (Padasana, Silasana, Bajrasana)

Om Prasada Sthiti Sarira

Civa Suci Nirmala Ya Namah Svaha Artinya :

Ya Tuhan, dalam Siwa suci tak ternodai, hamba telah duduk dengan tenang.

b) Pranayama :

1. Puraka (menarik nafas)

Om Ang Namah

2. Kumbaka (menahan nafas)

Om Ung Namah

3. Recaka (mengeluarkan nafas)

Om Mang Namah

Artinya :

Om Sanghyang Widhi Wasa, Pencipta, Pemelihara, dan Pelebur alam semesta hamba puja Dikau.

\section{c) Kara Sodhana (Sarira Suddha)}

Om soddha mam svaha

Om ati soddha mam svaha

Artinya :

Om Sanghyang Widhi Wasa, sucikanlah hamba dari segala dosa.

d) Puja Tri Sandhya :

Bait I :

Om om om

bhur bhuvah svah

tat savitur varenyam

bhargo devasya dhimahi

dhiyo yo nah pracodayat

Artinya :

Om Sang Hyang Widhi Wasa yang menguasai ketiga dunia ini, Engkau Maha Suci, sumber segala cahaya dan kehidupan, berikanlah budi nurani kami penerangan sinar cahaya-Mu Yang Maha Suci.

Bait II :

Om Narayana evedam sarvam yad bhutan yac ca bhavyam, niskalanko niranjano nirvikalpo nirakhyatah suddo devo eko narayanah na dvitiyo asti kascit

Artinya :

Om Sanghyang Widhi Wasa, sumber segala ciptaan, sumber semua makhluk dan kehidupan, Engkau tak ternoda, suci murni, abadi dan tak ternyatakan. Engkau Maha Suci dan tiadalah Tuhan yang kedua.

Bait III :

Om tvam sivas tvam mahadevah

Isvarah paramesvarah,

brahma visnus ca rudras ca purusah parikirtitah.

Artinya :

Om Sanghyang Widhi Wasa, Engkau disebut juga Siwa, Mahadewa, Brahma, Wisnu dan juga Rudra, karena engkau adalah asal mula segala yang ada.

\section{Bait IV :}

Om papo ham papakarmaham papatma papasambhavah trahi mam pundarikaksah sabahya bhyantarah sucih.

Artinya :

Om Sanghyang Widhi Wasa, hambaMu penuh kenestapaan, nestapa dalam perbuatan, jiwa, kelahiran. Karena itu oh Hyang Widhi, selamatkanlah 
hamba dari kenestapaan ini, dan sucikanlah lahir bathin hamba.

Bait V :

Om ksamasva mam mahadevah sarvaprani hitankarah mam moca sarva papebyah palaayasva sadasiva.

Artinya :

Om Sanghyang Widhi Wasa, Yang Maha Utama, ampunilah hamba-Mu, semua makhluk Engkau jadikan sejahtera, dan engkau bebaskan hamba-Mu dari segala kenestapaan atas tuntunan suci-Mu oh penguasa kehidupan.

\section{Bait VI :}

Om ksantavyah kayiko dosah

ksantavyo vaciko mama

ksantavyo manaso dosah

tat pramadat ksamasva mam.

Om Santih Santih Santih Om.

Artinya :

Om Sanghyang Widhi Wasa, ampunilah segala dosa dariperbuatan, ucapan, dan pikiran hamba, semoga segala kelalaian hamba itu Engkau ampuni. Om Sang Hyang WidhiWasa, Semoga damai di hati, damai di dunia, dan damai selalu.

Dilanjutkan dengan kramaning sembah. Adapun urutan-urutan Kramaning sembah, baik pada waktu sembahyang sendiri ataupun sembahyang bersama adalah sebagai berikut:

Persiapan penyucian sarana upakara sembahyang : a) Mantra penyucian dupa :

Om Ang Dupa dipaastra ya namah

Artinya :

Ya Tuhan dalam wujudmu sebagai Brahma, tajamkanlah nyala dupa kami, sehingga seperti sinar-Mu.

b) Mantra Penyucian Bunga :

Om Puspadanta ya namah

Artinya :

Ya Tuhan semoga bunga ini cemerlang dan suci.

\section{Sembah tanpa bunga (Muyung)}

Mantra :

Om Atma Tattvatma Soddha Mam Svaha

Artinya :

Ya Tuhan dalam wujud atma atau jiwa, dan kebenaran, bersihkan dan sucikanlah hambamu.

2. Menyembah Sanghyang Widhi Wasa sebagai Sanghyang Aditya dengan sarana bunga.

Mantra :

Om Adityasyaparam jyoti

Rakta tejo namo'stute

Svetapankaja madhyasthah

Bhaskarayo namo'stute

Artinya :

Om Sanghyang Widhi Wasa, sinar Surya Yang Maha Hebat, Engkau bersinar merah, hormat pada-Mu, Engkau yang berada di tengah-tengah teratai putih, hormat pada-Mu pembuat sinar.

3. Ketiga, Sembahyang kepada Tuhan 
dengan Ista Dewata Puja dengan sarana kwangen / bunga sbb :

Mantra :

Om nama deva adhi sthana ya

Sarva vyapi vai siva ya

Padmasana eka pratistha ya

Ardhanareswaryai namo namah

Om Sarasvati namastobhyam

Varade kama rupini

Siddha rambham karisyami

Siddhir bhavantu me sada

\section{Artinya :}

Ya Tuhan hamba memuja-Mu sebagai pemberi berkah, yang selalu memberikan karunia dan keberhasilan.

4. Keempat, Sembahyang kepada Tuhan untuk nunas panugrahan :

Mantra :

Om Anugrahaka Mano Haram

Deva Datta Nugrahakam

Arcanam Sarva Pujanam

Namah Sarva Nugahakam

Om Deva Devi Maha Siddhi

Yajnanga Nirmalatmaka

Laksmi Siddhisca Dirghayuh

Nirvigna Sukha Vrddhis Ca

Om Gring Anugraha Arcana Ya Nama

Namah Svaha

Om Gring Anugraha Manohara Ya Nama Namah Svaha

5. Kelima, Sembah Puyung / Matur Suksma sbb :

Mantra :

Om Dewa Suksma Paramacintya Ya Nama Svaha

Om Santih, Santih, Santih, Om.

Artinya :

Ya Tuhan, terima kasih kusampaikan
Semoga damai, damai, damai.

Acara berikutnya adalah persiapan pewintenan saraswati yang khusus diikuti oleh siswa kelas I baru dengan maksud dan tujuan agar para siswa baru memiliki kesucian jasmani dan rohani dalam mengikuti proses pendidikan selanjutnya. Melalui kesucian itulah para siswa memohon anugerah Sang Hyang Widhi Wasa dalam wujud keberhasilan dalam mengikuti pendidikan.

Adapun pelaksanaannya sebagai berikut :

\section{Mejaya-jaya}

Upacara mejaya-jaya urutannya sebagai berikut : pertama mengaturkan / ngaturan bakti dengan kwangen yang berisi sesari (uang) 11 kepeng dilanjutkan dengan memasang sirowista di kepala yang maksud dan tujuannya untuk menerima kekuatan agar pendengaran, penglihatan dan alat pembau menjadi tajam. Melaba yakni dengan natab penyeneng, dan banten Saraswati serta nglungsur isi daripada banten Saraswati. Melalui kesucian itulah para siswa dimaksud dimohonkan anugerah kehadapan Ida Sang Hyang Widhi Wasa untuk dapat berhasil dalam mengikuti pendidikan.

Fungsi dari upacara pawintenan ini dimaksudkan adalah untuk nyangaskara yaitu menyucikan seseorang dalam memasuki suatu bidang profesi tertentu. Upacara penyucian ini hampir selalu kita jumpai dalam pelaksanaan hidup beragama Hindu. Byakala, prayascita, pengelukatan, dan pebersihan adalah banten-banten yang mengantarkan orang mendapatkan kesucian jasmani maupun rohani ; sebagaimana disebutkan dalam kitab (Manawadharmasastra V 108) sebagai berikut :

Adbhir gatrami suddhyati 
Manah satyena suddhyati

Vidyatapobhyam bhutatma

Buddir jnanena suddyat

Artinya :

Tubuh dibersihkan dengan air

Pikiran disucikan dengan kebenaran

Jiwa dibersihkan dengan pelajaran suci dan tapa

Budi dibersihkan dengan pengetahuan.

Dengan upacara pawintenan ini maka seseorang telah dikukuhkan dalam profesi tertentu. Pengukuhan ini memberi hak kepada yang bersangkutan untuk melaksanakan profesinya sesuai dengan sesana (norma) profesinya. Dalam hal ini seorang siswa boleh melakukan kegiatan menulis, membaca dan mempelajari ilmuilmu tertentu (Putra Pudhasta, Suata, Surada : 2003) dalam bukunya yang berjudul : "Pedoman Pewintenan Saraswati Pelaksanaan Upacara Upanayana dan Samawartana dalam Sistem Pendidikan Agama Hindu di Indonesia". Selesai pawintenan Saraswati selanjutnya pemangku ngantukan Ida Betara yaitu upacara untuk mengembalikan manifestasi Tuhan (Ida Sang Hyang Widhi Wasa) yang dimohonkan hadir pada upacara tersebut untuk kembali ke stananya masing-masing, dan keseluruhan upacara Melalui kesucian itulah para siswa dimaksud dimohonkan anugerah kehadapan Ida Sang Hyang Widhi Wasa untuk dapat berhasil dalam mengikuti pendidikan.

Fungsi dari upacara pawintenan ini dimaksudkan adalah untuk nyangaskara yaitu menyucikan seseorang dalam memasuki suatu bidang profesi tertentu. Upacara penyucian ini hampir selalu kita jumpai dalam pelaksanaan hidup beragama Hindu. Byakala, prayascita, pengelukatan, dan pebersihan adalah banten-banten yang mengantarkan orang mendapatkan kesucian jasmani maupun rohani ; sebagaimana disebutkan dalam kitab (Manawadharmasastra V 108) sebagai berikut :

Adbhir gatrami suddhyati

Manah satyena suddhyati

Vidyatapobhyam bhutatma

Buddir jnanena suddyat

Artinya :

Tubuh dibersihkan dengan air

Pikiran disucikan dengan kebenaran

Jiwa dibersihkan dengan pelajaran suci dan tapa

Budi dibersihkan dengan pengetahuan.

Dengan upacara pawintenan ini maka seseorang telah dikukuhkan dalam profesi tertentu. Pengukuhan ini memberi hak kepada yang bersangkutan untuk melaksanakan profesinya sesuai dengan sesana (norma) profesinya. Dalam hal ini seorang siswa boleh melakukan kegiatan menulis, membaca dan mempelajari ilmuilmu tertentu (Putra Pudhasta, Suata, Surada : 2003) dalam bukunya yang berjudul : "Pedoman Pewintenan Saraswati Pelaksanaan Upacara Upanayana dan Samawartana dalam Sistem Pendidikan Agama Hindu di Indonesia". Selesai pawintenan Saraswati selanjutnya pemangku ngantukan Ida Betara yaitu upacara untuk mengembalikan manifestasi Tuhan (Ida Sang Hyang Widhi Wasa) yang dimohonkan hadir pada upacara tersebut untuk kembali kestananya masing-masing, dan keseluruhan upacara persembahyangan saraswati telah berakhir.

\subsubsection{Makna Filosofis dari Persembahyangan Saraswati dan Pawintenan}

Salah satu dari sekian banyak hari-hari suci Hindu adalah Hari Saraswati. Hari Saraswati adalah hari raya agama Hindu yang jatuh pada hari sabtu (saniscara) 
umanis wuku watugunung sebagai hari pemujaan kepada Sang Hyang Aji Saraswati, manifestasi Tuhan Yang Maha Esa sebagai Dewi Ilmu Pengetahuan. Manifestasi Hyang Widhi ini dilambangkan dengan seorang Dewi membawa: rebab, genitri, pustaka suci, teratai, dan berstana diatas bunga teratai.

Kata saraswati itu sendiri terdiri dari 2 kata yaitu : saras yang berarti sesuatu yang mengalir atau ucapan dan wati berarti : sesuatu yang mempunyai sifat. Jadi Saraswati berarti: yang mempunyai sifat mengalir. Sesuatu yang bersifat mengalir tidak lain adalah air, seperti air di sungai. Oleh karena itu ada sungai yang dianggap suci oleh umat Hindu yakni sungai Saraswati di India. Selain air ada juga yang memiliki sifat mengalir yakni : ilmu pengetahuan dan yang menguasai pengetahuan itu adalah Tuhan Yang Maha Esa yang bermanifestasi sebagai Dewi Saraswati. Oleh karena itu Dewi Saraswati adalah sumber ilmu pengetahuan dan kebijaksanaan. Dewi Saraswati itu sendiri adalah manifestasi Hyang Widhi Wasa yakni Dewa Brahma manifestasi Tuhan sebagai pencipta. Berdasarkan konsepsi diatas maka ilmu pengetahuan digambarkan sebagai Dewi Saraswati yang berwajah cantik jelita. Makna yang hendak diungkap dalam penggambaran tentang ilmu pengetahuan sebagai Dewi yang sangat cantik adalah : bahwa "Ilmu Pengetahuan itu sangat menarik untuk dipelajari seperti seorang lelaki tertarik dengan wanita cantik, demikian pula halnya bahwa setiap orang akan tertarik dengan ilmu pengetahuan. Ilmu pengetahuan yang dipersonifikasikan sebagai seorang Dewi yang cantik, digambarkan memiliki berbagai atribut. Semua atribut yang terdapat dalam wujud Dewi Saraswati memiliki makna filosofis sebagai berikut.

a) Daun Lontar adalah symbol-simbol sumber ilmu pengetahuan.

b) Teratai adalah symbol kesucian dari ilmu pengetahuan.

c) Genitri adalah symbol bahwa ilmu pengetahuan tidak akan pernah habis untuk dipelajari.

d) Rebab adalah symbol bahwa ilmu pengetahuan itu memiliki nilai-nilai estetika.

e) Angsa adalah symbol wiweka atau kebijaksanaan yang dapat membedakan antara yang baik dan yang buruk.

f) Bulu Burung Merak adalah symbol yang melambangkan kewibawaan.

Oleh karena itulah maka Umat manusia wajib berlomba-lomba mengejar ilmu pengetahuan. Dengan memiliki ilmu pengetahuan seseorang dapat hidup dengan sempurna serta bijaksana seperti layaknya orang biasa tanpa terpengaruh oleh hal-hal yang bersifat keduniawian.

Sedangkan Pawintenan Saraswati memiliki makna filosofis adalah Nyangaskara yakni menyucikan seseorang dalam memasuki suatu bidang atau profesi tertentu, yang dalam hal ini diperuntukkan bagi para pelajar yang mulai memasuki jenjang sekolah tertentu agar mendapat anugerah dari Sang Hyang Widhi Wasa sebagai Sang Hyang Saraswati, agar berhasil menuntut ilmu dan keterampilan serta dapat mengamalkannya untuk kesejahteraan, kedamaian, dan kesempurnaan hidup.

\subsubsection{Nilai-nilai Pendidikan Agama Hindu}

\section{a. Aspek Tattwa (Moral)}

Persembahyangan Saraswati tidak lain adalah untuk merenungkan diri (mulat sarira) yakni: sejauh mana kita sudah mampu memiliki dan menguasai ilmu pengetahuan serta seberapa jauh kita telah mendalami dan memahami ajaran-ajaran suci yang terdapat dalam kitab suci Veda, 
sebagai tuntutan untuk mencapai tujuan hidup yang tertinggi yakni bersatu dengan Brahman sebagai pemilik ilmu pengetahuan. Hal ini baru akan berarti apabila kita telah memahami ajaran-ajaran suci yang terdapat dalam kitab suci Veda dan meyakini bahwa Veda adalah buku suci yang wajib diketahui oleh setiap orang sehingga segala rahasia yang tersembunyi dalam buku / kitab suci Veda tersebut dapat dirasakan maknanya.

Dalam Lontar Medangkamulan tentang arti Persembahyangan Saraswati disebutkan bahwa Dewi Saraswati memiliki dua peranan dalam kehidupan manusia yaitu : (1) menganugerahkan ucapan halus dan benar kepada mereka yang memujanya, serta dilandasi dengan cinta kasih sayang sehingga tidak mengganggu hubungan antara sesama. (2) Menganugerahkan budhi yang baik sehingga manusia dapat membedakan mana perbuatan baik dan mana yang tidak baik. Untuk menghadirkan kedua anugerah tersebut maka perlu dilakukan pemujaan terhadap Dewi Saraswati sebagai prayacita (penyucian).

Dengan anugerah Dewi Saraswati maka seseorang akan memperoleh kebijaksanaan dan ucapan bagaikan amrta.

\section{b. Aspek Etika (Sosial Budaya)}

Dalam setiap pelaksanaan upacara keagamaan maka akan selalu menjunjung tinggi adat istiadat setempat yakni : kuna dresta dan loka dresta sebagai bagian dari nilai budaya local (kearifan lokal).

Aspek budaya dalam melaksanakan persembahyangan Saraswati dan Pawintenan Saraswati bagi siswa baru di SD No. 1 Denbantas meliputi dua hal yaitu :

(1) Budaya dalam hal berbusana atau berpakaian dan (2) budaya dalam hal sarana dan prasarana persembahyangan. Budaya dalam hal berbusana (berpakaian) khususnya dalam hal persembahyangan Saraswati dan Pawintenan Saraswati bagi siswa baru, mengedepankan nilai-nilai seni dan estetika atau keindahan. Busana yang digunakan dalam persembahyangan Saraswati dan Pawintenan Saraswati bagi siswa baru memiliki syarat sebagai berikut : bersih, suci, rapi dan sopan atau beretika, tetapi dalam kenyataannya sering dijumpai adanya ketimbangan-ketimbangan terutama dari segi estetika. Seiring dengan perkembangan jaman, busana persembahyangan selalu mengikuti perubahan atau inovasi utamanya dalam hal estetika dan keindahannya. Perubahan tersebut secara tidak langsung dapat merubah makna dari busana persembahyangan Agama Hindu itu sendiri (Kaler : 2004 : 6). Menurut Gusti Arya Panca Putra, kelihan adat Br. Tuakilang dalam wawancara tanggal 10 Desember 2013, mengatakan bahwa dalam persembahyangan umumnya, dan persembahyangan Saraswati khususnya, busana siswa SD No. 1 Denbantas umumnya mengikuti trend / mode terkini dimana gaya busananya cenderung agak transparan, menggunakan kain diatas lutut untuk putri demikian pula bagi siswa putra, yang selalu menonjolkan penggunakan destar (udeng) dan kekancutan yang aneh-aneh. Perubahan-perubahan gaya tersebut tentu akan merubah makna yang dapat mengurangi bahkan cenderung menghilangkan nilai-nilai budaya, adat dan tradisi yang sepantasnya dilestarikan agar tetap dapat dipertahankan karena nilai-nilai adat dan budaya tersebut sudah dikenal di manca negara.

\section{c. Aspek Ritual (Upacara)}

Nilai pendidikan seni budaya juga terdapat dalam pembuatan sarana upakara pada persembahyangan Saraswati dan Pawintenan Saraswati. Banten merupakan sarana upakara terpenting dalam setiap persembahyangan dan selalu berpedoman pada makna serta simbol-simbol dari Bhuwana Alit dan Bhuwana Agung untuk dipersembahkan kehadapan Ida Sang Hyang Widhi Wasa, manifestasi Tuhan sebagai 
Sang Hyang Aji Saraswati.

Banten-banten tersebut memiliki nilai pendidikan yang sangat tinggi karena bahanbahan yang digunakan dalam pembuatannya selalu menggunakan bahan segar dan bernilai gizi, bersih serta suci secara sekala niskala. Tetapi dalam kenyataannya belakangan ini sering dijumpai bahwa banten-banten yang dipersembahkan kehadapan Ida Sang Hyang Widhi dengan berbagai manifestasinya terbuat dari bahanbahan yang terbungkus dari plastik seperti makanan ringan siap saji, teh kotak, poccari sweat, dsb. Hal ini sangat tidak sesuai dengan budaya kita dan cenderung berpikir praktis yang dapat menurunkan arti dan makna budaya Hindu yang kita banggakan.

Sedangkan bahan-bahan yang semestinya dipakai sesuai dengan budaya kita seperti : ketupat, pisang, jaja begina, jaja uli, sirat, jaja gipang, apem, satuh, bulung dan sebagainya mulai jarang dipergunakan. Hal inilah yang perlu di benahi agar nilai-nilai budaya maupun tradisi yang telah diwariskan oleh pendahulu kita masih tetap dapat kita lihat dan tidak punah ditelan budaya modern yang belum tentu lebih baik.

Jadi nilai-nilai pendidikan yang terkandung dalam persembahyangan Saraswati dan Pawintenan Saraswati bagi siswa baru di SD No. 1 Denbantas ditinjau dari ketiga aspek diatas adalah : bahwa dengan menguasai ilmu pengetahuan maka seseorang akan memiliki Viveka (wiweka) yaitu dapat membedakan mana yang baik dan mana yang buruk. Ini akan dapat memberi arah dan tuntunan dalam menjalani kehidupan menuju kebahagiaan yang kekal abadi sekala dan niskala (Moksartham Jagadhitaya Ca Itti Dharma).

\subsection{Penutup}

Berdasarkan hasil penelitian dapat ditarik simpulan sebagai berikut :
1. Persembahyangan Saraswati di Sekolah Dasar No. 1 Denbantas dilaksanakan secara rutin setiap 210 hari yaitu: pada hari Saniscara Umanis Watugunung untuk memuja keagungan Sang Hyang Aji Saraswati dalam manifestasi Tuhan sebagai penguasa ilmu pengetahuan. Penguasaan terhadap ilmu pengetahuan dapat mengantarkan umat manusia menjadi bijaksana dan memiliki wiweka yakni mampu membedakan mana yang baik dan mana yang buruk, mana yang boleh dan mana yang tersesat.

Dalam pelaksanaannya cenderung masih terfokus pada kegiatan ritualnya saja, sedangkan aspek tatwa dan susilanya masih dikesampingkan. Seyogyanya ketiga aspek tersebut dapat dilakukan secara utuh dan seimbang agar persembahyangan tersebut bermakna dan menjadi sempurna.

2. Persembahyangan Saraswati dan Pawintenan Saraswati bermakna bahwa dengan menguasai ilmu pengetahuan maka seseorang akan memiliki wiweka, yang dapat memberi arah dalam menjalani kehidupan menuju kebahagiaan yang kekal abadi sesuai dengan tujuan Agama Hindu yakni "Moksartham Jagadhitaya Ca Itti Dharma".

3. Bahan-bahan yang dipakai sebagai sarana perlengkapan upakara atau banten sebaiknya menggunakan bahan-bahan yang segar dan bersifat alami serta memprioritaskan sumber daya alam lokal, bukan dari bahanbahan sintetis. Dengan demikian akan dapat melestarikan nilai-nilai budaya tradisional yang kita banggakan. 


\section{DAFTAR PUSTAKA}

Poerwadarminta, 1986. Kamus Bahasa Indonesia Edisi I. Departemen Pendidikan dan Kebudayaan Jakarta.

Koentjaraningrat, 1987. Sejarah Teori Antropologi I. Jakarta Universitas Indonesia.

Mukajir, 1990. Tentang Studi Kepustakaan. Wiana, 1992. Sembahyang Menurut Hindu. Yayasan Dharma Naradha.

Koentjaraningrat,1992. Antropologi Sosial. Dian Rakyat Jakarta.

Wiana 1994. Bagaimana Umat Hindu Menghayati Tuhan, Jakarta:Manik Geni.

PHDI Pusat, 1993. Pedoman Pembinaan Umat Hindu Dharma Indonesia. Jakarta : Upada Sastra.

Kajeng dkk. 1997. Sarasamuscaya. Paramita, Surabaya

Darwin, 1999 ; 53. Tentang Penyajian Analisis Data.

Soehardi, 2001. Pengantar Metodologi Penelitian Sosial-Bisnis, Manajemen. Yogyakarta : BPFE UST.

Bungin, Burhan, 2001. Metodologi Penelitian Sosial. Surabaya : Airlangga University Press.

Iqbal, H. 2002. Metodologi Penelitian dan Aplikasinya. Jakarta : Gi Halva Indonesia.

Sura, Pudharta, Suata, Surada. 2003. Tentang Pedoman Pawintenan Saraswati Pelaksanaan Upacara Upanayana dan Sama Wantana dalam Sistem Pendidikan Agama Hindu di Indonesia. Denpasar Kanwil Departemen Agama Propinsi Bali.

UU RI No. 20 tahun 2003 Tentang Sistem Pendidikan Nasional.

Putra Pudhastra, Suata dan Surada. 2003 : 3-

15. Pedoman Pawintenan Saraswati Pelaksanaan Upacara Upanayana dan Sama Wartana dalam Sistem Pendidikan Agama Hindu di Indonesia.

Wandri dan Sukrawati. 2005 : Acara Agama Hindu II.

Budiono, 2005. Kamus Ilmiah Populer Internasional. Surabaya : Alumni Surabaya.

Suhardana, 2006. Pedoman Sembahyang Umat Hindu.

Sri-Srimad AC. Bhakti Vedanta, Swami Prabupada. Bhagavadgita Menurut Aslinya. Hanuman Sakti.

Sugiyono, 2007. Metode Penelitian Kualitatif, Kuantitatif dan $R$ \& $D$. Bandung Alfabeta.

PHDI Kabupaten Karangasem, 2009 : Filosofis Sembahyang, Arti dan Makna Sembahyang. Amplapura.

Tim Penyusun, 2009. Buku Pedoman Penulisan Sekripsi Fakultas Ilmu Agama Universitas Hindu Indonesia.

Keputusan Seminar Kesatuan Tafsir terhadap Aspek-aspek Agama Hindu, Hari Saraswati dari Segi Tattwa dan Upacara. 